\title{
Aceitação sensorial e caracterização de frozen yogurt de leite de cabra com adição de cultura probiótica e prebiótico
}

\author{
Sensorial acceptance and characterization of goat's milk frozen yogurt with addition of probiotic \\ culture and prebiotic
}

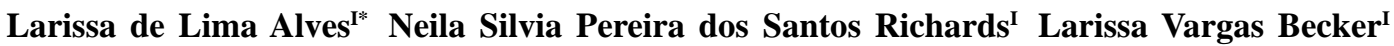 \\ Diego Fontana de Andrade ${ }^{I I}$ Liana Inês Guidolin Milani ${ }^{I}$ Ana Paula de Souza Rezer ${ }^{I}$ \\ Gustavo Callegari Scipioni"II
}

RESUMO

O leite de cabra é recomendado para pessoas intolerantes ao leite de vaca e/ou portadoras de desordens gastrintestinais. Frozen yogurt elaborado a partir de iogurte de leite de cabra foi acrescido de 1\% de prebiótico (inulina), $0,25 \%$ de cultura starter (Streptococcus thermophilus $e^{2}$ Lactobacillus bulgaricus) e 0,25\% de cultura probiótica (Bifidobacterium animalis e Lactobacillus acidophilus) para verificar seu potencial probiótico (após sete e 120 dias de armazenamento), sua qualidade físico-química e sua aceitação sensorial. Durante a estocagem, houve redução de células viáveis da flora microbiana, principalmente dos probióticos. Ainda assim, o produto apresenta potencialidade probiótica pela soma de $\boldsymbol{B}$. animalis e L acidophilus atingir o mínimo desejável até o fim do armazenamento. Os valores de extrato seco total $(26,6 \pm 0,2 \%)$, proteína $(3,0 \pm 0,2)$, gordura (2,6 $\pm 0,1 \%), p H(5,5 \pm 0,01)$ e ácido láctico $(0,2 \pm 0,01 \%)$ encontram-se semelhantes aos relatados em outros trabalhos para o mesmo produto. A avaliação sensorial foi realizada por 50 provadores não treinados em teste com escala hedônica de sete níveis e intenção de compra. O produto recebeu bons escores para aparência global, cor, aroma e sabor; já textura e sabor residual obtiveram menores índices de aceitação. $\mathrm{Na}$ intenção de compra, $61 \%$ dos avaliadores declararam que comprariam o produto, contra $39 \%$ que não comprariam. Nessas condições, demonstra-se a viabilidade de elaboração de frozen yogurt de leite caprino acrescido de pre- e probióticos.

Palavras-chave: Bifidobacterium animalis, Lactobacillus acidophilus, inulina.

\section{ABSTRACT}

Goat's milk is recommended for people afflicted with cow milk intolerance and gastro-intestinal disorders. Frozen yogurt was elaborated with $1 \%$ prebiotic (inulin), $0.25 \%$ starter culture (Streptococcus thermophilus and Lactobacillus bulgaricus) and $0.25 \%$ probiotic culture (Bifidobacterium animalis and Lactobacillus acidophilus) to verify probiotic potential (after 7 and 120 days of storage), physical-chemical quality and sensorial acceptance. During storage viable cells were reduced, mainly probiotic bacteria. Nevertheless, the product showed probiotic potential because of $\boldsymbol{B}$. animalis and $\mathbf{L}$. acidophilus sum, which reached the minimum desirable until the end of storage. Values of total dry matter (26.6 $\pm 0.2 \%)$, protein $(3.0 \pm 0.3 \%)$, fat $(2.6 \pm 0.1 \%), p H(5.5 \pm 0.01)$ and acid lactic $(0.2 \pm 0.01 \%)$ were similar to those descript by other researches for the same product. Sensorial evaluation was realized by 50 untrained panelists, with a 7-point hedonic scale and intention to purchase. The product received good scores for global appearance, color, aroma and taste. Texture and residual taste had lower acceptance rates. The intent to purchase showed that $61 \%$ of panelists asserted to buy the product against 39\%, who would not buy it. Accordingly, this research showed the feasibility of elaborating the goat's milk frozen yogurt with addition of pre- and probiotics.

Key words: Bifidobacterium animalis, Lactobacillus acidophilus, inulin.

\section{INTRODUÇÃO}

O consumo regular de alimentos fermentados como o iogurte é reconhecidamente benéfico para a manutenção da boa saúde. Esse efeito é atribuído, em parte, às bactérias ácido-lácticas Streptococcus salivarius ssp. termophilus e Lactobacillus delbrueckii ssp. bulgaricus utilizadas na elaboração do produto e dotadas de propriedades

IDepartamento de Tecnologia e Ciência de Alimentos, Centro de Ciências Rurais (CCR), Universidade Federal de Santa Maria (UFSM), 97105-900, Santa Maria, RS, Brasil. E-mail: larissafarm@yahoo.com.br. *Autor para correspondência.

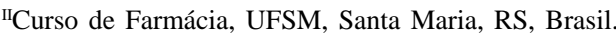

IIICurso de Agronomia, UFSM, Santa Maria, RS, Brasil. 
terapêuticas (INOUE et al., 1998). Além dessas culturas, bactérias probióticas, tais como Bifidobacterium e Lactobacillus, têm sido incorporadas ao iogurte a fim de ampliar seu apelo de alimento funcional. As culturas probióticas são definidas como suplementos alimentares que beneficiam quem as consome por manter e/ou melhorar o balanço intestinal (FULLER, 1989), além de reduzir a intolerância à lactose, controlar infecções intestinais, reduzir a propensão a alguns carcinomas e melhorar o flavor e qualidade nutricional dos alimentos que as contêm (DAVIDSON et al., 2000).

Sabor agradável e textura atrativa são essenciais para os produtos lácteos enriquecidos com probióticos. Nesse aspecto, o sorvete tipo frozen yogurt torna-se uma alternativa conveniente para o fornecimento destes na dieta. O frozen yogurt é obtido a partir da fermentação do leite por meio da ação do Streptococcus thermophilus e Lactobacilus bulgaricus, ou a partir de iogurte com ou sem a adição de outras substâncias alimentícias, sendo posteriormente aerado e congelado. Desse modo, associa o valor nutricional do iogurte com o sabor refrescante do sorvete, além de apresentar shelf-life maior que sua matéria-prima. Outra característica ímpar do frozen yogurt é seu sabor leve, em razão do baixo teor de gordura quando comparado ao sorvete.

Alguns estudos (HEKMAT \& McMAHON, 1992; INOUE et al., 1998; ALAMPRESE et al., 2005) têm demonstrado que é possível produzir frozen yogurt com adição de probióticos. No entanto, os microorganismos devem sobreviver à estocagem a frio (ALAMPRESE et al., 2005), para assegurar a quantidade mínima satisfatória $\left(10^{5}-10^{7} \mathrm{UFC}^{-1}\right)$ (UYSAL et al., 2003). O processo de congelamento/descongelamento causa sérios danos às células, levando à inibição da multiplicação e/ou atividade metabólica (efeito subletal) ou à morte (efeito letal) (ALAMPRESE et al., 2005). Por outro lado, oligossacarídeos como a inulina têm recebido atenção por sua atividade prebiótica. Esse ingrediente não digerível presente como material de reserva de algumas plantas tem a capacidade de aumentar o número e/ou atividade de micro-organismos específicos no trato intestinal, com ação peculiar sobre Bifidobacterium e Lactobacillus (GIBSON \& ROBERFROID, 1995; BURITI et al., 2007; SILVA, 2007).

O leite de cabra, por sua vez, é descrito como um produto de alta digestibilidade e potencial alergênico inferior ao leite de vaca, sendo aconselhado para dieta infantil, de idosos e nos casos de intolerância ao leite de vaca (HAENLEIN, 2004; ALFÉREZ et al., 2003). Apesar disso, o leite caprino possui sabor característico proporcionado pela presença de ácidos graxos de cadeia curta (capróico, caprílico e cáprico), com baixa aceitação sensorial por boa parcela da população não habituada ao seu consumo. Contudo, alguns procedimentos tecnológicos adotados na elaboração do frozen yogurt, tais como homogeneização e estocagem a frio, são apontados como capazes de reduzir o sabor característico do leite de cabra (MORGAN \& GABORIT, 2001). Sendo assim, a elaboração de frozen yogurt a partir de leite caprino acrescido de pre- e probiótico é interessante não apenas pelo efeito probiótico do produto, mas também por oferecer à população intolerante ao leite de vaca uma alternativa alimentar atraente.

O objetivo deste trabalho foi elaborar frozen yogurt de leite de cabra, sabor morango, contendo prebiótico (inulina) e probióticos (Bifidobacterium animalis e Lactobacillus acidophilus) a fim de avaliar sua qualidade físico-química e aceitação sensorial. Além disso, buscou-se verificar a potencialidade probiótica do produto durante o armazenamento.

\section{MATERIAL E MÉTODOS}

\section{Elaboração do frozen yogurt}

Para o preparo do iogurte, foram utilizadas duas culturas concentradas para inoculação direta (Chr. Hansen, Valinhos, São Paulo, Brasil): uma cultura starter contendo Streptococcus termophilus e Lactobacillus delbrueckii ssp. bulgaricus (Rich ${ }^{\circledR}$ ) e outra contendo os micro-organismos probióticos Bifidobacterium Bb12 e Lactobacillus acidophilus LA-5 (Bio-Rich ${ }^{\circledR}$ ). Para preparo da cultura-mãe, um grama de cada cultura (contendo 1,0 x $10^{6} \mathrm{UFC} \mathrm{g}^{-1}$ de cada um dos quatro micro-organismos) foi inoculado em $100 \mathrm{ml}$ de leite de cabra UHT previamente esterilizado em autoclave a $121^{\circ} \mathrm{C} 15 \mathrm{~min}^{-1}$.

Duas replicatas de seis litros de leite de cabra UHT comercial acrescidos de $8 \%$ (p/v) de açúcar e 1\% (p/v) de inulina (Raftiline HP-Gel, Orafti, Bélgica) foram autoclavadas a $121^{\circ} \mathrm{C} 15 \mathrm{~min}^{-1}$, para eliminar possíveis contaminações desses ingredientes. Após resfriamento até $40-43^{\circ} \mathrm{C}$, a mistura recebeu $0,5 \%$ de cultura-mãe (contendo 0,25\% de cultura starter e 0,25\% de cultura probiótica), sendo posteriormente incubada a 42 $( \pm 0,5)^{\circ} \mathrm{C}$ até atingir $\mathrm{pH} 4,8$ (cerca de $4 \mathrm{~h}$ ). Após a fermentação, o iogurte foi transferido para refrigerador, onde permaneceu a $4^{\circ} \mathrm{C}$ até o dia seguinte, quando foram acrescentados os demais ingredientes para o preparo do frozen yogurt: 3\% de creme pasteurizado (50\% de gordura) (UNI-UFSM, Santa Maria, RS, Brasil), $7 \%$ de glicose, $4 \%$ de polpa de morango, $1 \%$ de aroma de morango, $1 \%$ de liga neutra e $1 \%$ de estabilizante Emustab $^{\circledR}$ (Duas Rodas Industrial, Jaraguá do Sul, SC), com homogeneização em liquidificador industrial. Após 
essa etapa, a mistura seguiu para sorveteira industrial (MDG Equipamentos, modelo MH 80.6, série A238, São Carlos, SP, Brasil), a fim de o produto adquirir a consistência e aeração típica. O frozen yogurt foi acondicionado em embalagens próprias para sorvete (250 ml), mantidas em freezer refrigerador a $-18^{\circ} \mathrm{C}$ até as análises.

\section{Análises físico-químicas}

A caracterização físico-química foi realizada entre um e cinco dias de armazenamento do produto, em triplicata. O teor de extrato seco total foi obtido por secagem em estufa a $105^{\circ} \mathrm{C}$ até peso constante; a proteína foi obtida conforme método de Kjehdahl (fator de conversão 6,38); a gordura foi obtida em butirômetro de Gerber; o pH foi obtido por medida em pHmetro digital (Digimed, DM 20, SP Labor, Presidente Prudente, SP, Brasil) e a acidez titulável foi obtida por titulação com $\mathrm{NaOH} 0,1 \mathrm{~N}$ até $\mathrm{pH}$ 8,2, seguindo metodologias propostas por PEREIRA et al. (2001) para gelados comestíveis.

\section{Análises microbiológicas}

As contagens das culturas starter/ probióticas foram realizadas em duplicata no iogurte antes da elaboração do frozen yogurt e no $7^{\circ}$ e no $120^{\circ}$ dia de estocagem do produto, para comparar a viabilidade das culturas na matéria-prima e no início/ fim do período de validade. Para tal, $25 \mathrm{~g}$ de amostra foram misturados com $225 \mathrm{ml}$ de água peptonada (Vetec Química, Rio de Janeiro, RJ, Brasil). Diluições subsequentes foram preparadas, e o número de células viáveis foi determinado em uma alíquota de $1 \mathrm{ml}$ pela técnica pour plate. S. termophilus foi enumerado em meio M17 ágar (Fluka Biochemika, Sigma-Aldrich Chemie, Steinheim, Suíça), com adição de $5 \%$ de solução de lactose a $10 \%$, seguida de incubação aeróbica a $37^{\circ} \mathrm{C} / 48 \mathrm{~h}$ (IDF, 1999). MRS-ágar (Himedia Laboratories, Mumbai, Índia) foi ajustado para pH 5,4 com ácido acético glacial, e incubação anaeróbica a $37^{\circ} \mathrm{C} / 72 \mathrm{~h}$ foi usada para enumeração de $\boldsymbol{L}$. delbrueckii ssp. bulgaricus (IDF, 1997). L. acidophilus foi contado em MRS-ágar (Himedia Laboratories, Mumbai, India), com $10 \%$ de solução de maltose 20\% (IDF, 1999); a maltose permite somente o crescimento desse micro-organismo. Para contagem das colônias de $\boldsymbol{B}$. animalis, foi usado MRS-ágar (Himedia Laboratories, Mumbai, India), com adição de $100 \mathrm{ml}$ de solução de glicose a $20 \%$, 5ml de solução de dicloxacilina a 0,01\%,10ml de solução de cloreto de lítio a 11,11\% e 5ml de solução de cloreto de cisteína a $10 \%$ para cada $1000 \mathrm{ml}$ de meio de cultura; seguido de incubação anaeróbica a $37^{\circ} \mathrm{C} / 72 \mathrm{~h}$ (CHR HANSEN, 1999).
Análise sensorial

Cerca de $50 \mathrm{ml}$ de frozen yogurt foram oferecidos em potes plásticos para um painel de 50 provadores não treinados, escolhidos conforme disponibilidade. A análise sensorial foi realizada em cabines individuais com luz branca artificial, e a ficha sensorial apresentava parâmetros de avaliação quanto à aparência global, à cor, ao aroma, à textura, ao sabor e ao sabor residual; este último importante quando se trata de derivados do leite de cabra. Foi adotada escala hedônica não estruturada de sete pontos (1-desgostei muitíssimo, 4-indiferente e 7-gostei muitíssimo) (DUTCOSKY, 1996). Paralelamente, os analistas foram questionados na mesma ficha quanto à intenção de compra do produto.

\section{Análise estatística}

O pacote estatístico SPSS 8.0 for Windows foi usado para calcular as médias, os desvios-padrão e as diferenças estatísticas pelo Teste de Tukey, a 5\% de significância.

\section{RESULTADOS E DISCUSSÃO}

\section{Avaliação físico-química}

A legislação brasileira atual não dispõe de padrões de identidade e qualidade para frozen yogurt especificamente; nesse caso, adota-se a Resolução RDC n. 266, de 22 de setembro de 2005, da Agência Nacional de Vigilância Sanitária (ANVISA), que aprova o regulamento técnico para fixação de identidade e qualidade de gelados comestíveis, preparados, pós para o preparo e bases para gelados comestíveis, para efeitos de comparação (BRASIL, 2005).

O teor de extrato seco total do frozen yogurt (26,6 $\pm 0,2 \%)$ está de acordo com a portaria citada, a qual exige um mínimo de $26 \%$ de sólidos totais. O conteúdo protéico também atende à especificação, e o valor obtido $(3,0 \pm 0,3 \%)$ está acima do mínimo recomendado (2,5\%). Valores semelhantes de proteína foram encontrados por DALLA CORTE (2008) para frozen yogurt à base de leite de vaca contendo a mesma concentração de pre- e probióticos deste trabalho. $\mathrm{O}$

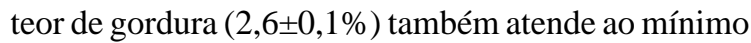
exigido (2,5\%). Segundo GUINARD et al. (1994), a gordura do leite favorece a qualidade do frozen yogurt por melhorar suas características sensoriais, proporcionando melhor sabor e textura mais macia e cremosa. Além disso, os glóbulos de gordura do leite de cabra são menores que os do leite de vaca, favorecendo a digestibilidade do produto (FURTADO, 1986). 
A portaria supracitada não contempla padrões de $\mathrm{pH}$ e acidez para gelados comestíveis. $\mathrm{O}$ valor de pH encontrado $(5,5 \pm 0,01)$, no entanto, está de acordo com INOUE et al. (1998) e HEKMAT \& McMAHON (1992), que relatam pH em torno de 5,5 como sendo o melhor aceito em avaliação sensorial de frozen yogurts com diferentes pHs. O mesmo ocorre para o percentual de ácido láctico $(0,2 \% \pm 0,01)$, semelhante ao encontrado pelos mesmos autores para o frozen yogurt com $\mathrm{pH}$ 5,5.

\section{Avaliação microbiológica}

As contagens dos micro-organismos starter e probióticos na matéria-prima (iogurte) e no frozen yogurt com sete e 120 dias de estocagem (Tabela 1) demonstram que a exposição a baixas temperaturas afeta a viabilidade das culturas já na primeira semana. Os micro-organismos starter mostraram-se mais resistentes ao processo, principalmente Streptococcus termophilus, com número de células estável e não diferente estatisticamente durante todo o período de avaliação. LOPEZ et al. (1998), no estudo de frozen yogurts comerciais, afirmam que o gênero Streptococcus é mais resistente ao congelamento que o Lactobacillus, mesmo por um período de armazenamento superior a quatro meses. L. bulgaricus reduziu 1,8 ciclos logarítmicos desde a elaboração do iogurte até o fim da estocagem, sendo estatisticamente diferente em todas as análises; resultado semelhante foi obtido por MILES \& LEEDER (1981), que relatam decréscimo de 0,5 e 1 ,5log UFC $\mathrm{ml}^{-1}$ para $\boldsymbol{S}$. termophilus e $\boldsymbol{L}$. bulgaricus, respectivamente, em frozen yogurt armazenado a $-29,9^{\circ} \mathrm{C}$.

Ambas as culturas probióticas diminuíram acentuadamente o número de células viáveis. Bifidobacterium animalis reduziu 2,2 ciclos logarítmicos desde o iogurte até o $120^{\circ}$ dia, sendo

Tabela 1 - Contagens ${ }^{*}$ (log UFC $\mathrm{ml}^{-1}$ ) de micro-organismos starter (Streptococcus termophilus e Lactobacillus bulgaricus) e probióticos (Bifidobacterium animalis e Lactobacillus acidophilus) em iogurte e frozen yogurt de leite de cabra durante estocagem.

\begin{tabular}{lccc}
\hline & Iogurte 1 dia & $\begin{array}{c}\text { Frozen yogurt } \\
7 \text { dias }\end{array}$ & $\begin{array}{c}\text { Frozen yogurt } \\
120 \text { dias }\end{array}$ \\
\hline S. termophilus & $9,2^{\mathrm{a}}$ & $9,1^{\mathrm{a}}$ & $9,0^{\mathrm{a}}$ \\
L. bulgaricus & $6,5^{\mathrm{a}}$ & $5,2^{\mathrm{b}}$ & $4,8^{\mathrm{c}}$ \\
B. animalis & $6,1^{\mathrm{a}}$ & $5,1^{\mathrm{b}}$ & $3,9^{\mathrm{c}}$ \\
L. acidophilus & $9,4^{\mathrm{a}}$ & $6,8^{\mathrm{b}}$ & $4,8^{\mathrm{c}}$ \\
\hline
\end{tabular}

${ }^{*}$ Médias de dois experimentos independentes. Diferentes letras na mesma linha indicam diferença estatística pelo Teste de Tukey $(\mathrm{P}<0,05)$. estatisticamente diferente nas três situações. Aliado ao congelamento/manutenção a baixas temperaturas que naturalmente contribuíram para tal perda, há relatos que esse gênero é sensível a mudanças de $\mathrm{pH}$, acidez e presença de oxigênio, condições encontradas no frozen yogurt por sua matéria-prima naturalmente ácida e seu processo de aeração (overrun) (DAVIDSON et al., 2000). BAIG \& PRASAD (1995) encontraram redução de apenas um ciclo logarítmico de Bifidobacterium animalis em frozen yogurt, porém em tempo de armazenamento inferior (90 dias) ao deste estudo.

L. acidophilus apresentou brusco declínio (2,6 ciclos logarítmicos) desde a matéria-prima até o $7^{\circ}$ dia de armazenamento; no entanto, após 120 dias reduziu apenas 1,9 ciclos logarítmicos, com diferença estatística significativa entre as avaliações. Decréscimo na mesma proporção foi encontrado por HEKMAT \& McMAHON (1992), ao armazenarem frozen yogurt com os mesmos probióticos deste estudo pelo mesmo período. HOLCOMB et al. (1991) não observaram evidências de injúria pelo frio em $\boldsymbol{L}$. acidophilus exposto a $-5^{\circ} \mathrm{C}$, por 6 h, enfatizando a influência do fator tempo/temperatura de exposição do produto na viabilidade desse micro-organismo.

A legislação brasileira atual (BRASIL, 2007) preconiza número mínimo de probióticos apenas para leites fermentados, sendo o gênero Bifidobacterium o único micro-organismo contemplado. Apesar de o número de células viáveis de Bifidobacterium animalis não atingir esse mínimo $\left(10^{6} \mathrm{UFC} \mathrm{g}^{-1}\right)$ no frozen yogurt, justifica-se o apelo probiótico do produto pela presença concomitante de $\mathbf{L}$. acidophilus, dotado das mesmas propriedades probióticas. Portanto, a soma dos dois micro-organismos atende ao mínimo considerado ideal para promover efeitos benéficos ao organismo durante todo o período de estocagem. Além disso, foi utilizada concentração de cultura probiótica inferior $(0,25 \%)$ aos demais trabalhos disponíveis na literatura para frozen yogurt, visando a elaborar um produto menos oneroso para a indústria, mas sem perder a potencialidade probiótica.

\section{Avaliação sensorial}

No teste com escala hedônica, os avaliadores atribuíram médias de notas para aparência geral $(5,2 \pm 0,8)$, cor $(5,2 \pm 0,9)$ e aroma $(5,5 \pm 0,9)$ na faixa relativa aos termos hedônicos "gostei" e "gostei muito”. INOUE et al. (1998), ao analisarem frozen yogurts com diferentes $\mathrm{pHs}(5,0 ; 5,5,6,0)$, perceberam que esse fator influenciou a aceitação global, sendo o de $\mathrm{pH}$ 5,5 (semelhante ao $\mathrm{pH}$ do frozen yogurt deste trabalho) o de melhor aceitação. 
A variação de $\mathrm{pH}$ está diretamente relacionada à acidez e esta, por sua vez, ao aroma do produto. A atividade das culturas lácticas causa mudanças químicas específicas, liberando compostos voláteis com grupamento carbonil, como ácido láctico e acético, acetaldeído, cetonas e diacetil (TAMIME \& ROBINSON, 2007), que contribuem para a percepção de acidez, aroma e sabor do frozen yogurt. Ademais, a avaliação do aroma é importante quando se trata de derivados do leite caprino, em razão do seu odor característico (MORGAN \& GABORIT, 2001). Contudo, o fato de o leite caprino ser utilizado na elaboração do frozen yogurt parece não ter afetado seu aroma, obtendo escore intermediário entre "gostei” e "gostei muito".

A avaliação da textura em sorvetes e assemelhados engloba diversas percepções gustativas, como arenosidade, cremosidade, maciez e corpo, diretamente relacionadas com o pH e teor de gordura do produto (INOUE et al., 1998). A inulina, mesmo presente em baixas concentrações, é capaz de influenciar as características texturais, melhorando a cremosidade, aeração e viscosidade (KIP et al., 2006). No entanto, o frozen yogurt tradicionalmente apresenta conteúdo lipídico reduzido quando comparado ao sorvete. Uma vez que os provadores estão habituados ao consumo desse segundo produto, a falta de gordura pode ter afetado negativamente a avaliação da textura do frozen yogurt, que apresentou baixa média de notas $(4,8 \pm 0,8)$ em relação aos demais parâmetros sensoriais avaliados.

O sabor do leite de cabra é bastante característico, oriundo da presença dos ácidos graxos de cadeia curta (capróico, caprílico e cáprico) no leite e consequentemente em seus derivados (MORGAN \& GABORIT, 2001). Entretanto, é relatado que o processamento do leite de cabra reduz esse sabor desagradável, como pode ser confirmado pela média de notas desse atributo $(5,0 \pm 0,7)$, classificado na faixa de "gostei". A presença de ácidos graxos de cadeia curta também influenciou o sabor residual, percebido mais intensamente e pouco aceito pelos provadores $(4,0 \pm 0,9)$. Além disso, a presença de probióticos pode ter afetado o sabor pela liberação adicional de ácidos como parte do metabolismo desses micro-organismos (MAN \& JONES, 1996).

Ao indagar os provadores a respeito da intenção de compra do frozen yogurt, $61 \%$ dos avaliadores declararam que comprariam o produto contra 39\% que não o adquiririam, provavelmente em razão do sabor pronunciado do leite de cabra ao qual não estão habituados.

\section{CONCLUSÃO}

Os resultados mostram a viabilidade da produção de frozen yogurt de leite de cabra com adição de pre- e probióticos, dada a qualidade físico-química e microbiológica deste, a aceitação sensorial quanto a diversos parâmetros e a intenção de compra por parte dos avaliadores. Desse modo, surge uma alternativa para a indústria laticinista de oferecer um produto com apelo probiótico e de custo reduzido em relação aos demais produtos do gênero, dada a baixa concentração de cultura utilizada neste trabalho

\section{AGRADECIMENTO}

Os autores agradecem à Usina Escola de Laticínios (UNI-UFSM) pelo fornecimento de ingredientes utilizados na elaboração do produto e apoio técnico durante a elaboração deste.

\section{COMITÊ DE ÉTICA}

Este trabalho não passou por avaliação de comitê de ética porque na época em que foi realizado não havia tal obrigatoriedade para trabalhos com avaliações sensoriais.

\section{REFERÊNCIAS}

BRASIL. Ministério da Agricultura, Pecuária e Abastecimento. Instrução Normativa n. 146 de 23 de outubro de 2007. Regulamento técnico de identidade e qualidade de leites fermentados. Diário Oficial da União, 24 out. 2007. Seção 1, p.5. Disponível em: <http://extranet.agricultura.gov.br/sislegisconsulta/consultarLegislacao.do?operacao=visualizar\&id=18164. Acesso em 25 ago. 2008.

BRASIL. Ministério da Saúde. Agência Nacional de Vigilância Sanitária. Resolução RDC n. 266 de 22 de setembro de 2005. Regulamento técnico para fixação de identidade e qualidade de gelados comestíveis e, preparados para gelados comestíveis, pós para o preparo e bases para gelados comestíveis. Diário Oficial da União, 23 set. 2005. Disponível em: <http:// www.anvisa.gov.br/e-legis>. Acesso em 01 jun. 2009.

ALAMPRESE, C. et al. Effects of Lactobacillus rhamnosus GC addition in ice cream. International Journal of Dairy Technology, v. 58, n. 4, p. 200-206, 2005. Disponível em: $<$ http://www3.interscience.wiley.com/cgi-bin/fulltext/ 118668043/PDFSTART>. Acesso em 25 ago. 2008. doi: 10.1111/j.1471-0307.2005.00214.x.

ALFÉREZ, M.L. et al. Dietary goat milk improves iron viability in rats with induced ferropenic anaemia in comparasion with cow milk. Journal of Dairy Research, v.70, n.2,p.181187,2003. Disponível em: <http://journals.cambridge.org/ action $/$ display Abstract ? from Page $=$ online $\&$ aid $=150273>$. Acesso em 25 ago. 2008. doi: 10.1017/S0022029903006058.

BAIG, M.I.; PRASAD, V. Biochemical characteristics and stability of Bifidobacterium bifidum in frozen yogurt supplemented with condensed cheese whey. Journal Dairy Foods Home Science, v.15, p.99-108, 1995. 
BURITI, F.C.A. et al. Synbiotic potential of fresh cream cheese supplemented with inulin and Lactobacillus paracasei in co-culture with Streptococcus termophilus. Food Chemistry, v.104, n.4, p.1605-1610, 2007. Disponível em: <http://www.sciencedirect.com/ science?_ob=MImg\&_imagekey=B6T6R-4N7S593-1$1 \&$ _cdi $=5037 \&$ \&user $=687358 \&$ \&orig $=$ search \&_coverDate $=1$ 2\%2F31\%2F2007\&_sk=998959995\&view=c\&wchp=dGLzVlzzSkWb\&md5=7d1ff1390de0a8330e $1 \mathrm{f} 8 \mathrm{ff} 7 \mathrm{f} 53 \mathrm{effd} 5 \& \mathrm{ie}=/$ sdarticle.pdf. Acesso em: 30 ago. 2008. doi: 10.1016/ j.foodchem.2007.03.001.

CHR. HANSEN. Method for counting probiotic bacteria. Lactobacillus acidophilus, Lactobacillus casei and Bifidobacteria in milk products made with nutrish cultures. Horsholm, Dinamarca, 1999. 9p. [Guideline].

DALLA CORTE, F.F. Desenvolvimento de frozen yogurt com propriedades funcionais. 2008. 97f. Dissertação de Mestrado (Ciência e Tecnologia de Alimentos) - Universidade Federal de Santa Maria, RS.

DAVIDSON, R.H. et al. Probiotic culture survival and implications in fermented frozen yogurt chacacteristics. Journal of Dairy Science, v.83, n.4, p.66-673, 2000. Disponível em: <http://jds.fass.org/cgi/reprint/83/4/666.pdf>. Acesso em: 27 ago. 2008.

DUTCOSKI, S.D. Análise sensorial de alimentos. Curitiba: Champagnat, 1996. 122p.

FULLER, R. Probiotics in man and animals. Journal Applied Bacteriology, v.66, p. 365-378, 1989.

FURTADO, M.M. Fabricação de queijo de leite de cabra. 6.ed. São Paulo: Nobel, 1986. 125p.

GIBSON, G.R.; ROBERFROID, M.B. Dietary modulation of the human colonic microbiota: introducing the concept of prebiotics. Journal of Nutrition, v.125, p.1401-1412,1995. Disponível em: <http://jn.nutrition.org.w10050.dotlib.com.br/ cgi/reprint $/ 125 / 6 / 1401$ ? maxtoshow $=$ \&HITS $=10$ \&hits $=10 \& \mathrm{R}$ ES ULTFORM AT $=\&$ s e a r chid $=1 \&$ FIR S T IN DEX $=$ $0 \&$ sortspec $=$ relevance $\&$ firstpage $=1401 \&$ resourcetype $=$ HWCIT $>$. Acesso em: 20 ago. 2008.

GUINARD, J.-X. et al. Effect of sugar and acid on the acceptability of frozen yogurt to a student population. Journal of Dairy Science, v.77, n.5, p.1232-1238, 1994. Disponível em: <http://jds.fass.org/ $\mathrm{cgi} / \mathrm{reprint} / 77 / 5 / 1232$ ? maxtoshow $=\&$ HITS $=10 \&$ hits $=10 \& \mathrm{R}$ ESULTFORMAT $=\&$ and orexactfulltext $=$ and \& sea $\mathrm{r} \mathrm{c} \mathrm{h} \mathrm{i} \mathrm{d}=1$ \& F I R S T I N D E X $=0$ \& s or t s p e c $=$ relevance \&volume $=77 \&$ firstpage $=1232$ \&resourcetype $=$ HWCIT $>$. Acesso em: 20 ago. 2008.

HAENLEIN, G.F.W. Goat milk in human nutrition. Small Ruminant Research, v.51, n.2, p.155-163, 2004. Disponível em: <http:// www.sciencedirect.com/science?_ob=MImg\&_imagekey=B6TC5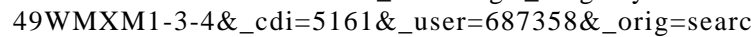

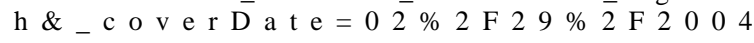
\&_s k $=999489997 \&$ vie w $=$ c \& w ch p $=$ d G L b VzW zSkzk\&md5=956accedf7ade245ee0cc1248962de9d\&ie=/ sdarticle.pdf $>$. Acesso em 15 ago. 2008. doi: 10.1016/ j.smallrumres.2003.08.010.

HEKMAT, S.; McMAHON, D.J. Survival of Lactobacillus acidophilus and Bifidobacterium bifidum in ice cream for use as a probiotic food. Journal of Dairy Science, v.75, n.6, p.14151422, 1992. Disponível em: < http://jds.fass.org/cgi/reprint/75/6/ 1415 ? maxtoshow $=$ \&HITS $=10$ \&hits $=10$ \& RESULTFOR
M A T $=\&$ a n d or ex a c t t i t l e $=$ a n d \& a n d o rexacttitleabs $=$ and $\&$ andorexactfulltext $=a n$ $\mathrm{d} \& \mathrm{~s}$ e a r c h i d $=1 \&$ F I R S T I N D E X $=0$ \& s o r t s p e c $=$ r elevance $\&$ volume $=75 \&$ firstpage $=1415 \&$ resourcetype $=$ HWCIT $>$. Acesso em 28 ago. 2008.

HOLCOMB, J.E. et al. Viability of Lactobacillus acidophilus and Bifidobacterium bifidum in soft-serve frozen yogurt. Cultured Dairy Products Journal, v.26, n.3, p.4-5, 1991.

INOUE, K. et al. Preparation and properties of ice cream type frozen yogurt. International Journal of Dairy Technology, v.51, n.2, p.44-50, 1998. Disponível em: <http:// www3.interscience.wiley.com/cgi-bin/fulltext/119136574/ PDFSTART>. Acesso em 25 ago. 2008.

INTERNATIONAL DAIRY FEDERATION. Yogurt: enumeration of characteristic microorganisms. Bruxelas, Bélgica. IDF/ISO Standard, 1997. 5p.

INTERNATIONAL DAIRY FEDERATION. Detection and enumeration of Lactobacillus acidophilus. Bruxelas, Bélgica. Bulletin of the IDF, n.306, p.23-33, 1999.

KIP, P. et al. Inulins improve sensoric and textural properties of low-fat yoghurts. International Dairy Journal, v.16, n.9, p.10981103, 2006. Disponível em: <http://www.sciencedirect.com/ science?_ob=ArticleListURL\&_method=list\&_ArticleListID $=92675120$ $4 \&$ _ s ort $=$ d \& vi e w $=$ c \&_a c ct $=$ C $000037899 \&$ ve rsion $=1 \&$ _urlversion $=0 \&$ _us erid $=68735$ $\overline{8} \& m d 5=0 \mathrm{c} 5 \mathrm{~d} 4 \mathrm{~d} 690 \overline{4} \mathrm{~d} 7 \mathrm{~b} 1 \mathrm{ca} 055 \mathrm{e} 8 \mathrm{~b} 2 \mathrm{~b} 6088 \mathrm{~d} 0 \mathrm{e} 1>$. Acesso em: 27 ago. 2008. doi: 10.1016/j.idairyj.2005.10.011.

LOPEZ, M.C. et al. Survival of lactic acid bacteria in commercial frozen yogurt. Journal of Food Science, v.63, n.4, p.706708, 1998. Disponível em: <http://www3.interscience.wiley.com/ cgi-bin/fulltext/119109548/PDFSTART>. Acesso em: 10 ago. 2008.

MAN, C.M.D.; JONES A.A. Shelf life evaluation of foods. Brno: Aspen Publication, 1996. 321p.

MILES J.J; LEEDER, J.G. Starter culture viability in frozen yogurt. Cultured Dairy Products Journal, v.16, p.12-14, 1981.

MORGAN, F.; GABORIT, P. The typical flavour of goat milk products: technological aspects. International Journal of Dairy Technology, v.54, n.1, p.38-40, 2001. Disponível em: <http://www3.interscience.wiley.com/cgi-bin/fulltext/ 119029597/PDFSTART>. Acesso em: 10 ago. 2008.

PEREIRA, D.B.C. et al. Físico-química do leite e derivados: métodos analíticos. 2.ed. Juiz de Fora: EPAMIG, 2001. $234 p$.

SILVA, S.V. Desenvolvimento de iogurte probiótico com prebiótico. 2007. 107f. Dissertação de Mestrado ( Ciência e Tecnologia de Alimentos) - Universidade Federal de Santa Maria, RS.

SPSS for Windows -Release 8.0.0. Chicago. SPSS, 1997. 1 CD-ROM.

TAMIME, A.Y.; ROBINSON, R.K. Tamime and Robinson's yoghurt: science and technology. 3.ed. Cambridge: CRC, 2007. 791p.

UYSAL, H. et al. Some properties of set yoghurt made from caprine milk and bovine-caprine milk mixtures fortified by ultrafiltration or the addition of skim milk powder. International Journal of Dairy Technology, v.56, n.3, p.177-181, 2003. Disponível em: <http://www3.interscience.wiley.com/cgi-bin/ fulltext/118852163/PDFSTART>. Acesso em 20 ago. 2008.

Ciência Rural, v.39, n.9, dez, 2009. 